\title{
ÉTICA, CIÊNCIA E FORMAC̣ÃO DE PROFESSORES: A ESCOLA NA SOCIEDADE CONTEMPORÂNEA
}

\begin{abstract}
RESUMO: $O$ presente artigo, resultante de em uma pesquisa qualitativa cujo instrumento foi a revisão bibliográfica, aborda, a partir de uma reflexão sobre o desenvolvimento da ciência e os conceitos de ética, direcionamentos para a formação de professores e para sua atuação na escola contemporânea. O texto, fundamentado nos apontamentos sobre a ciência e a ética, traz para discussão o papel da escola no processo de formação do indivíduo, considerado produtor e inserido em uma sociedade tecnológica atravancada por discussões de caráter ético. A análise aponta para a necessidade de, com maior intensidade, conjugar a ética ao processo de estruturação da ciência e aos processos de formação docente, sendo este um caminho para sua maior presença no cotidiano da escola.

Palavras-chave: Ética; Ciência; Formação de professores.
\end{abstract}

\section{ETHICS, SCIENCE AND TEACHER EDUCATION: THE SCHOOL IN CONTEMPORARY SOCIETY}

ABSTRACT: This paper is the result of a qualitative research based on review of the literature, and discusses, from reflections on the development of science and concepts of ethics, directions for teacher formation and their role in contemporary school. The paper, based on notes about science and ethics, brings to discussion the role of school on the formation of individuals, as a producer and inserted within a technological society hampered by ethical discussions. The analysis indicated the need to incorporate ethics into the processes of science structuring and teacher formation with greater intensity, which is a way to increase its presence in everyday school life.

Keywords: Ethics; Science; Teacher education.

\section{Vilmar Malacarne* Dulce Maria Strieder ** Dartel Ferrari de Lima***}

*Doutor em Educação pela Universidade de São Paulo (USP). Professor Adjunto da Universidade Estadual do Oeste do Paraná (UNIOESTE). Email: mala@unioeste.br

* *Doutora em Educação pela Universidade de São Paulo (USP). Professora de Física no Centro de Ciências Exatas e Tecnológicas e no Programa de Pós-Graduação em Educação (mestrado) do Centro de Educação, Comunicação e Artesda Universidade Estadual do Oeste do Paraná(UNIOESTE. Email:dmstrieder@unioeste.br * * * Graduado em Fisioterapia, Mestre em Engenharia Biomédica e dotorando em Medicina Preventiva pela USP.SP. Professor do Centro de Ciências Humanas, Educação e Letras da Universidade Estadual do Oeste do Paraná - UNIOESTE Marechal Cândido Rondon/PR. Email: dartel@rondotec.com.br 


\section{REFLEXÃO SOBRE A ESCOLA E A SOCIEDADE - UMA INTRODUÇÃO AO TEMA EM FOCO}

A sociedade brasileira é intrinsecamente pluralista, tendo em vista a heterogenidade do comportamento social. Isso implica, nomeadamente, que os aspectos próprios de cada contexto e suas diferenciações, estejam presentes de forma fundamentada e planejada na educação formal.

A possibilidade de escolher entre diferentes tipos ou sistemas de abordagens para o ensino é um dos fortes fatores de coesão social necessários para a inclusão da sociedade periférica. A esse respeito, o reconhecimento da escola como agente integrador traz contribuição significativa para a construção da cidadania.

A concentração na construção de uma realidade social mais equilibrada requer que a elaboração do conhecimento e o potencial para a aprendizagem permanente estejam subjacentes a todas as questões. Para Bris (2006), os indivíduos não podem estar satisfeitos com a simples aquisição de conhecimento, mas sim com o domínio de valores humanos, visando ao desenvolvimento harmonioso de uma sociedade livre e democrática cuja chave é o acesso dos mais amplos segmentos da população a uma boa educação presente e futura. Assim, vemos que a questão da democracia constitui um primeiro problema: a definição do conhecimento para todos.

A Educação, de acordo com Arendt (1990), carrega a responsabilidade não só do desenvolvimento da criança, mas também da continuidade do mundo. Por um lado, a criança deve ser cuidadosamente protegida e cuidada para que o mundo não a destrua, mas por outro lado, o mundo também precisa de uma proteção que impeça que ele seja devastado e destruído pelo recém-chegado e a cada nova geração que se segue.

Para Bechtel (2006), as sociedades mais desenvolvidas estão migrando, progressivamente, de uma economia industrial para uma economia na qual os investimentos são feitos em áreas-chave da educação, formação, investigação e das novas tecnologias, porém as economias periféricas parecem não estar direcionadas ao mesmo destino.

Na perspectiva de Barret (2009), a escola ainda está longe de abrir todas as portas para o sucesso social e funciona como uma máquina de reproduzir as desigualdades sociais. Em outras palavras, a ideia da escola democrática, servindo como uma alavanca para reduzir as desigualdades sociais, está representada como um mito enganoso, uma vez que a escola não cumpre exatamente o papel atribuído a ela.

O resultado dessa contradição é passível de identificação: a porta da escada social via escola está somente entreaberta, mantendo uma situação semelhante àquela de décadas atrás. Algumas razões podem estabelecer os parâmetros para essa crítica reflexiva. Inicialmente, é necessário traçar um mapa da escola no Brasil. Com o argumento da luta contra as disparidades existentes entre o cidadão comum e aquele mais abastado que poderia oferecer a seus filhos o ingresso nas melhores escolas, ou seja, em nome da equidade, decidiu-se que todos deveriam enviar cada vez mais as crianças às escolas e, para facilitar o acesso, a escola eleita deveria ser a mais próxima possível de suas casas. 
A divisão da sociedade em classes é visível na geografia das cidades. Então, os pobres, que vivem em bairros pobres, vão para escolas em locais pobres, construídas e mantidas para os pobres. Ricos, que vivem em bairros nobres, vão para as escolas para os ricos e, posteriormente, para a universidade. Basta ir até a saída de qualquer escola para se comprovar a diferenciação de classe social existente entre os seus frequentadores.

As crianças socialmente favorecidas, quando não estão na escola, elas estão em suas casas, em uma sala confortável, ou, frequentemente confiadas a um responsável que promoverá atividades de fortalecimento da aprendizagem. Para as crianças oriundas de meios desfavorecidos, seus atrativos principais se resumem a inatividade, distrações e aventuras nas ruas. Para a criança deixada a si mesma, o que ela perde na escola não se garante mais. Assim, uma forma ideológica, muitas vezes adaptada pela escola, produz consequências que fazem os pobres e os ricos permanecem prisioneiros no seu ambiente social. O pobre na pobreza e o rico na fartura.

A incapacidade da escola em atender as necessidades dos jovens e as dificuldades encontradas pelos gestores em aspectos como uma organização que estimule a aprendizagem, são a causa direta de uma nova desigualdade social. Mais genericamente, a atividade em todas as áreas e em todos os níveis da hierarquia educacional apresenta-se com um nível de complexidade sem precedentes.

Há outro fator, não menos importante: o abandono da autoridade do professor. Essa nova forma de anarquismo que coloca nas penas do anti-autoritarismo eleva a criança ao nível mais alto, em ser dada prioridade à sua livre expressão, sustentado na premissa do risco de limitar a sua criatividade, ou pior, estigmatizá-la - Assim, o estudante foi colocado no centro da escola, passando de um desequilíbrio para outro, pois a figura do professor e do conhecimento tornaram-se, agora, marginais ao sistema. (CHEVENEMENT, 2006).

Contudo, não se deve perder a perspectiva de que crianças e adolescentes também são educados por suas famílias, portanto, não cabem ao professor nem todos os méritos, nem todos os deméritos pelo resultado do processo educacional. A escola, na opinião do autor citado, tem como objetivo básico ensinar, e não, fazer os alunos felizes, não se descartando a possibilidade de que um pode causar o outro. Nós corroboramos com a ideia de que, em muitos momentos, a escola já não se destina fundamentalmente a educar os alunos e que, segundo Nóvoa (1999), a escola está se tornando cada vez mais uma instituição social assistencialista, e os professores, também, em muitos momentos, atuam com assistencialismo cada vez maior. A escola pública, basicamente, aceita esse grande naufrágio.

Conforme pressuposto de Pena-Ruiz (1999), se o conteúdo ensinado e aprendido na escola de hoje é inadequado para preparar os alunos para a vida política, econômica e social a que a sociedade aspira, a solução não é imaginar uma mudança de ideais, mas uma mudança profunda na política de educação. Para Bkouche et al (1991), a escola continua a ser, talvez não por muito tempo, um dos últimos lugares em que o homo sapiens se expressa; nesse sentido, é na inadequação que se encontra a força da escola. É também necessário que a escola crie meios de 
resistência e de como reivindicar essa inadequação.

Porém, essa política não deve se ater a um falso debate entre os defensores do conhecimento, aqueles que colocam o conhecimento no centro do ato de ensino, e aqueles que, em nome da formação, colocam os estudantes no centro do sistema de ensino, criando, assim, oposição a qualquer forma de entendimento entre o aluno e o conhecimento. A escola deve sim, marcar a resistência contra o sistema que procura reduzir o homem apenas ao seu valor de mercado, valor de mercado do produtor e valor para o consumidor. Não se pode reduzir a construção do conhecimento para a mera transmissão de informações. Pretende-se com isso, não só o conhecimento, mas uma reflexão sobre o conhecimento, e, essa atitude reflexiva não é espontânea. (TIM, 2003).

A desigualdade social está assim intensamente vinculada à desigualdade no conhecimento e ultrapassa os limites da simples desinformação. Um dos aspectos relevantes da desigualdade refere-se às questões próprias da ciência, de seu desenvolvimento e da tecnologia. Referindo-se à América Latina, Macedo e Katzkowicz (2003) comentam que: "continuar mantendo a maior parte da população como analfabetos científicos pressupõe um aspecto que só faz agravar os grandes traços de iniqüidade da região, inabilitando essa maioria de participar democraticamente na tomada de decisões (...)." (p. 67). Oferecer oportunidades para todos se engajarem em uma cultura científica e tecnológica de qualidade não está atrelado apenas a esforços limitados a uma perspectiva educacional, mas também à perspectiva ética e de compromisso social.

Para Zucco (2008), por meio de uma análise atenta das conotações da ciência contemporânea e dos seus agentes sociais podem ser encontrados os elementos para a construção de um novo pacto político entre a ciência, a sociedade e a educação, que não afete os direitos fundamentais da liberdade do conhecimento, da transparência e da partilha de escolhas. Ao mesmo tempo, é possível assumir a responsabilidade coletiva para com aqueles que, por dificuldades culturais e econômicas, estão à margem das possibilidades. $\mathrm{O}$ desconforto que é registrado na ciência decorre do sentimento de exclusão por parte do público: exclusão do conhecimento, entendido como uma falta de ferramentas para compreender e avaliar; exclusão das escolhas do conhecimento atrelada a uma economia globalizada; exclusão do acesso à educação para a inovação econômica, classe social, idade, entre outros.

No presente artigo, apresenta-se uma reflexão acerca dos elementos considerados centrais para o pacto político mencionado, sendo eles a Ciência, a sociedade e a educação, tendo como pano de fundo para tal discussão a questão da ética que impreterivelmente os constitui e os interrelaciona. Essa reflexão é resultado de uma pesquisa qualitativa, "que trabalha com o universo de significados, motivos, aspirações, crenças, valores, atitudes, o que corresponde a um espaço mais profundo das relações, dos processos e dos fenômenos que não podem ser reduzidos a operacionalização de variáveis" (MINAYO, 2002, apud LAKATOS e MARCONI, 2010, p. 271), onde o instrumento de investigação foi a revisão bibliográfica. 


\section{A CIÊNCIA NA SOCIEDADE CONTEMPORÂNEA}

O Renascimento foi um momento marcante da história do pensamento ocidental. Fundamentado e caracterizado culturalmente pelo humanismo antropocêntrico. Originado no esforço em renovar os paradigmas medievais, com inspiração na educação humanista idealizada na Roma antiga, buscava preparar o homem para o exercício de sua liberdade, com a inclusão de programas de poesia, história, filosofia, retórica e matemática, principalmente nos espaços de educação formal. A razão, em detrimento da fé, se fortaleceu na construção dos caminhos em busca do entendimento das coisas do e no mundo. As respostas divinas atribuídas aos fenômenos da natureza já não mais satisfaziam a curiosidade humana. Mesmo que a Ciência ainda não explicasse totalmente os porquês desses fenômenos, suas indicações ganham força e se instituem como novo modelo para a racionalidade em construção. A busca desse novo entendimento constituiu, assim, as bases do que se denomina Ciência Moderna já a partir do século XVII.

Nos primórdios do que comumente se denomina de antiguidade, a educação e a vida se estruturavam nos pressupostos do pensamento mítico. A ordem ou o caos surgem a partir do apelo a deuses e heróis. É principalmente com os gregos (século VI) que nasce a busca da explicação da natureza com base nela mesma, adotando fundamentos teóricos distintos daqueles definidos pela mitologia. Nessa perspectiva, foram os sofistas que primeiramente fizeram uma importante crítica a essa linha de saber. Apontavam eles para a necessidade de se estudar o homem em profundidade e de determinar o valor e o alcance de sua capacidade de saber, fugindo assim das explicações trascendentes para as coisas da natureza. As contribuições posteriores, de Sócrates, Platão e Aristóteles, predominaram por mais ou menos 19 séculos (320 a.C. - 1600 d.C.), de certa forma moldando os caminhos do pensamento, principalmente ocidental.

Quanto aos caminhos seguidos na instituição da racionalidade adotada na Idade Média, os principais pensadores serão Santo Agostinho e Tomás de Aquino, ainda que a influência de Platão e principalmente de Aristóteles sejam constantes. Essa nova perspectiva, que tem na Igreja Católica Apostólica Romana sua principal difusora e mantenedora, irá sacralizar-se e dogmatizar o conhecimento que até então tomava um caminho de libertação do trascendente.

Com a superação deste momento, a Idade Moderna se evidencia com a Revolução Científica do século XVII e com o Renascimento, este último se opondo aos saberes especulativo e contemplativo dos séculos anteriores que se instituíram. A modernidade surge como uma nova postura diante do mundo: o conhecimento não parte apenas de noções e princípios, mas da própria realidade observada e submetida à experimentação. Mais ainda, o saber deve retornar ao mundo para transformá-lo. Dá-se a aliança entre a Ciência e a técnica. Quebra-se com isso o modelo aristotélico de inteligibilidade: surge a questão do método. No centro dessa nova perspectiva, não está o conhecimento do ser, mas o problema do próprio conhecimento. Na busca por superar esse novo dilema, duas correntes 
opostas se firmaram: o racionalismo e o empirismo. O racionalismo se caracterizava em limitar o homem, em termos de sujeito de conhecimento, ao âmbito da própria razão. O empirismo, ao contrário, enfatizava a importância inequívoca da experiência sensível no processo cognitivo, e o limitava ao âmbito dessa experiência sensível. Como consequência, os racionalistas confiam na capacidade de o homem atingir verdades universais e eternas, já os empiristas questionam o caráter absoluto da verdade, já que o conhecimento procede de uma realidade em constante transformação, sendo tudo relativo ao espaço, ao tempo e ao humano.

Immanuel Kant, um dos últimos pensadores da Idade Moderna, e já precursor da Contemporaneidade, promoveu forte contribuição inovadora ao preconizar que os erros científicos do racionalismo e do empirismo são concepções equivocadas que ambos têm do conhecimento humano, seja por sustentar que o conhecimento procede só do sujeito ou só do objeto, seja por afirmar que o objeto pode fornecer só a novidade e o sujeito só a universalidade. Para o iluminista - linha de pensamento de que faz parte - o conhecimento científico é constituído por juízos sintéticos. A priori a ciência recebe do objeto a extensividade; do sujeito, a universalidade, que independem de experiências, são universais e necessários, enriquecem, ampliam e fazem progredir o conhecimento.

Com o Positivismo, que surge com Comte, enfatiza-se ainda mais o valor da experiência sensível das ciências, às quais cabe descobrir a invariabilidade dos fenômenos. Suas características investigatórias se baseiam na certeza sensível de uma observação sistemática e na certeza metódica, que garante acesso adequado aos fenômenos observados. Os fenômenos observados são relacionados a princípios que permitem combinar as observações isoladas, buscando relações com suas leis e se capacitando para prever e controlar os fenômenos para a construção de uma sociedade positiva (ordenada e progressista). O modelo de Ciência começa assim a ser construído e afirmado, tornando-se referência para a produção do conhecimento que se institui, buscando, aos poucos, fundamentar a cientificidade ao domínio da lógica-matemática, estabelecendo assim critérios que distinguissem enunciados científicos e não científicos. Nessa perspectiva, um conjunto de afirmações é verdadeiro se é possível descrever, verificar o fato ao qual se refere; um conjunto de asserções não verificáveis é desprovido e vazio de significado.

Não obstante, essa ciência se apresenta cada vez mais abrangente e torna-se um dos fatores essenciais ao desenvolvimento social e ao comportamento social, atuando não somente sobre os impactos na sociedade atual, mas também, sobre os efeitos na sociedade futura. Então, hoje, se faz necessário um modelo de Ciência seguramente mais crítico e mais ético em que não se negligenciem as consequências sociais de riscos potenciais, resultantes do arbítrio dos indivíduos nas suas escolhas do que é aceitável ou não, evitando, assim, a fragmentação da ordem social. 


\section{AS QUESTÕES DA ÉTICA}

No processo de constituição da Ciência contemporânea, ganha relevância o papel destinado à reflexão ética, principalmente pelo próprio processo de gigantismo que esta Ciência conquista, refletindo sobremaneira na vida das pessoas, principalmente com o advento da tecnologia. Nesse contexto, a preocupação em fundamentar o envolvimento ético com a prática e o desenvolvimento da Ciência se torna objeto premente de uma reflexão, que deveria chegar ao processo de formação inicial das novas gerações de "cientistas" via escola formal.

A ética não se limita a uma reflexão puramente teórica sobre o conteúdo e a aplicação dos valores morais. É inseparável da ação humana em geral e, principalmente, da educação, através das quais os próprios sujeitos se fazem sujeitos e se preparam para os processos de constituição. É, portanto, através da ética, em seus múltiplos contextos, que esses atores encontram guarida para estruturar e desenvolver habilidades práticas e conhecimentos de um para o outro e produzir conhecimento.

Os desafios do mundo da prática provocam, por vezes, conflitos entre aquilo a que o discurso se propõe e o que a prática constitui. Expressa a tática dos diferentes atores e as estratégias que adotam para a resolução desses conflitos, inclusive na construção de uma ética pessoal, constituindo as dimensões reflexivas sobre uma ética aplicada em seu poder exploratório. Assim, pensar nos contextos éticos não é simplesmente estabelecer a ética ou regras de conduta específicas para cada tipo de atividade, em vez disso, é iluminar os aspectos práticos da decisão de propor novos instrumentos para nova reflexão e ação.

A ética, então, não é separável da teoria da ação. Ela deriva sua significação a partir da aplicação prática dos princípios para o bem dos outros ou da equidade coletiva. Ela pressupõe a consciência de suas nascentes e seus efeitos reais, objetivando adquirir ou inventar formas de ser ético sem perder de vista a necessidade de reflexão aprofundada sobre as motivações e os meios para construir e desenvolver a humanidade.

A "ética na educação" permite associar cada vez mais os direitos e deveres envolvidos na tentativa de não se perder, ou seja, para encontrar um modus vivendi entre os valores pessoais, familiares, religiosos, profissionais, organizacionais e educacionais que são moldados com antecedência. Esse ato educativo não é redutível a uma simples transferência de conhecimento: implica uma aprendizagem de valores e se apresenta, antes de tudo, no despertar de consciência das questões éticas do estar coletivo.

A hipótese que orienta a atual reflexão é que a aplicação justa do direito à educação é inseparável da dimensão ética da relação com a educação e, mais especificamente, com a auto-estima e respeito pelos outros. Essa relação implica em como compreender a importância de cultivar um senso de sua própria dignidade, assegurando as condições para a liberdade de consciência e como entender o paradoxo de que uma consciência livre é também uma consciência treinada para ser livre. É fundamental para a ética e para a educação contemporânea, marcada pelas 
exigências da discussão intersubjetiva, o debate democrático.

A atual sociedade se apresenta pluralista, complexa e, às vezes, desconcertante. Indivíduos desta sociedade contextualizam a ética como um discurso da moda, no entanto, quando se trata de passar da retórica à realidade, muitas reservas estão surgindo. A ética não deveria ser tratada apenas como meio para ensinar o que se pode fazer ou não, com a pretensão de verdade. Assim, a ética poderia ser para a verdade um caminho de tolerância - vista como um dos mais altos valores éticos compartilhados em nossas sociedades democráticas, mas que deve ser sempre reinventada em um projeto para conquistar uma prática de (re) criação contínua e de (re) negociação, ao invés de determinar um valor de eternidade - de um modo de vida; a verdade do ser humano (RUSS, 1999).

A moralidade é uma dimensão da vida humana com raro equivalente e profundamente influenciada por diversos fatores culturais, históricos, religiosos, emocionais, racionais, motivacionais e educacionais. A moral e a ética são geralmente considerados sinônimos, pois os dois termos se originam da mesma direção, ou seja, supõem a disposição do caráter ou das atitudes de uma pessoa, de um grupo ou de uma dada cultura.

A ética, durante seu desenvolvimento através da história, tem obtido diferentes abordagens. Embora conceituada por diversos pensadores de renome, até o momento, não se encontrou a aprovação de uma abordagem universalizante. Para tentar entender o que cada uma dessas abordagens propõe, parece coerente iniciar com a análise da experiência da moral ao longo do tempo e do espaço. Assim, dois conceitos fundamentais são revelados: o de "valor" e o de "dever". Todos convivem com a realidade de que certas coisas são feitas e outras evitadas. Nesse domínio da ética, a inter-relação dos valores e deveres com a ciência e a sociedade é o foco desta reflexão.

As relações humanas têm elementos imutáveis e universais, mas também específicos e repletos de história. Estruturalmente, a moral é sempre a mesma, mas o seu conteúdo é variável, pelo menos em certa medida. Os valores morais mudam constantemente, mas, ao mesmo tempo, alguns deveres morais são constantes, refletindo os limites da lógica que segue para o discurso moral; por exemplo, o ato de não prejudicar os outros ou de dizer a verdade.

Um tema no debate de hoje sobre ciência e educação é o de determinar o quanto estas têm servido para moldar a sociedade e para transformar o moderno e o tradicional. Entre a ciência que nos diz o que é, e a moral, que nos diz o que deve ser, há um abismo intransponível. É esse hiato radical estabelecido que ficou conhecido como a "guilhotina de Hume" (CHAUÍ, 2001).

A educação em ciência é um processo social que tem como base a sua intenção de introduzir as pessoas e apoiá-las no processo de construção do patrimônio cultural representado pelo conhecimento e pelos processos da ciência, não se esquivando, também, da obrigação de permitir que os indivíduos e as comunidades evoluam a partir do desenvolvimento da consciência crítica e ética da ciência. Então, a educação em ciência, além de se preocupar com os conceitos de 
ensino, teorias e processos científicos, deve se esforçar para a emergência de uma reflexão crítica sobre os paradigmas e dogmas na base da sociedade moderna e da ciência em si (ROTH e DESAUTELS, 2002).

Nesse contexto, observa-se que várias concepções filosóficas da ciência têm um impacto sobre a conceituação deste inter-relacionamento - valor e dever. Enfatizando a ciência como uma atividade comprometida com base em valores, a confiança nela depositada tem diminuído. Uma visão mais radical poderia conceituar a ciência como uma atividade de rivalidade e concorrência. Latour (2007) assegura que a ciência é como a guerra, dada a incerteza sobre os valores básicos envolvidos.

Esta ciência se confronta com um paradoxo: há uma crescente necessidade de desenvolver um código de conduta que vise criar uma falta de certeza sobre o que um código desse tipo implica. Então, desenvolver um código não é apenas uma questão de identificar quais são os valores intrínsecos da ciência, mas também, uma questão de negociação destinada a criar novas perspectivas de confiança em relação à sociedade, onde os valores básicos da ciência, pelo menos, precisam estar conectados com o conceito de responsabilidade social.

Em seu desenvolvimento, a ciência tem proporcionado uma estrutura lógica que lhe permitiu ganhar algum prestígio na sociedade. Tanto assim que, para alguns, a ciência se tornou influente nas atitudes em relação a como os seres humanos evoluem. Mais ainda, ela se transformou em um modelo ideológico triunfante para toda a humanidade, uma espécie de benefício para todos (KAHN,1999).

$\mathrm{Na}$ sociedade high-tech atual, educação em ciência e tecnologia é absolutamente necessário. Porém, para Fourez (2002), após a explosão das primeiras bombas nucleares sobre as populações civis de Hiroshima e Nagasaki, algumas preocupações com o poder da ciência fortaleceram a reflexão sobre os valores explícitos e não explícitos que a ciência apresenta. A questão levantada é a dúvida em se poder construir o futuro da humanidade exclusivamente a partir do conhecimento científico e com o resultado de seus produtos.

Além disso, os laços estreitos entre o trinômio: ciência, educação e tecnologia, em relação ao poder político e econômico estão se tornando cada vez mais evidentes e preocupantes. Isso conduz a análise crítica dos objetivos, abordagens e produtos desta ciência. Para Maiz-Vallenilla (1974), a essência humana, no que se refere à qualidade, à competitividade e à lucratividade são palavras-chave que estão na ordem do dia nos projetos de pesquisa, públicos e privados. A ideia de que o desenvolvimento da ciência estimula e fomenta o desenvolvimento econômico é generalizada. Daí a preocupação crítica de que os produtos e os métodos da ciência devem entrar na arena do debate público no âmbito ético e educacional.

Nesse contexto, considera-se a educação científica como um tema da educação capaz de gerar e garantir o desenvolvimento equilibrado do meio social. Dessa forma, a educação em ciência não deveria ser guiada somente pelos valores da eficiência, da qualidade e do paradigma sociocultural e industrial, mas também, pela responsabilidade no acatamento dos deveres construtivos e transformadores que se esperam dela. (BERTRAND e VALOIS, 1999). 
Essa educação tem, então, a função de explicitar também o patrimônio cultural da ciência e como ela funciona. Dessa forma, estará sendo incentivada a autoconsciência da pessoa como cidadão participativo e criativo e, incluí-lo, como parte da educação nesta ciência. A partir da análise crítica dos princípios éticos, é possível promover um processo do despertar da consciência do papel de cidadão participativo.

Existem várias maneiras de conceber um bom relacionamento entre a Educação e a ciência. Nas sociedades ocidentais, onde a ciência e a tecnologia são valorizadas, aborda-se um determinado tipo de relação com a educação em que a ciência é guiada pela representação que os seres humanos fazem de si mesmo. Ela é e está lá para servi-lo. Nessa imagem das coisas, a ciência tem a missão fundamental de promover a melhor compreensão dos fenômenos do universo para melhor servir os cidadãos.

Mesmo na da cultura ocidental, que emergiu pensando dessa forma - de estar em relação com o conhecimento -, Habermas (1999) tem proposto outras formas de relações culturais da ética com a ciência. Neste caso, a cultura educacional da ética na ciência é vista como um processo de reflexão e análise sobre a relação com a ciência e sobre as maneiras de entrar em contato com ela.

A reflexão e o esclarecimento sobre a ética na ciência devem emergir em todas as atividades relativas ao ensino e à aprendizagem de conhecimentos, levando-se em conta a multidimensionalidade do ser humano, o que significa que os esforços educacionais na ética não se traduzem apenas no desenvolvimento racional e cognitivo, senão também, do emocional, social, espiritual, estético e moral. Para que se atinja esse objetivo, é necessário que se desperte na formação de formadores, a capacidade de refletir sobre a própria prática a partir de projetos e ações que investiguem a sua própria realidade, além do ensinar a ensinar continuado, da estruturação de novos conhecimentos, da capacidade de relacionar a teoria com a prática e da preparação para o trabalho e para a cidadania, propondo-se um diálogo pedagógico partilhado em busca das "três imagens do paraíso" propostas por Larrosa (2000): a) a compreenção do eu; b) a compreenção de minha formação e; c) a compreenção de minha transformação.

\section{A FORMAC̣̃̃O DE PROFESSORES NO DIÁLOGO COM A CIÊNCIA E A ÉTICA}

No estudo da formação de professores, Foster (2009) defende a formação como um projeto não virado para o passado, embora não o ignore, mas um projeto que transporta consigo alguma coisa de diferente daquilo que é o presente e, portanto, vislumbra utopicamente o futuro.

Para Tardif (2002), a expressão do professor - produção, transformação e mobilização de saberes - não pode estar desconectada de cinco pontos fundamentais: 1) saberes pessoais adquiridos antes de sua formação. Estes são oriundos da família, do ambiente, do grupo de amigos, etc.; 2) formação escolar anterior, influenciada pela escolaridade anterior à sua formação universitária; 3) formação 
específica para o magistério; 4) saberes adicionados, adquiridos por instrumentação paralela mediante cursos, leituras, reflexões, etc.; 5) experiência em sala de aula. Assim, todo professor tende a transpor para a sua prática, ou ter subjacente a ela, as experiências vivenciadas durante todo o seu percurso formativo, não apenas profissional, mas como pessoa.

Para o mesmo autor, o objetivo mor do sucesso de um professor é formar pessoas que não mais venham a necessitar de professores ao longo de sua existência como cidadão, portanto, capazes de dar sentido à sua própria vida e às suas ações, numa interação lado a lado - interação cooperativa - e não por interação face a face - interação de oposição.

Para Marin (2004), a educação voltada para a emancipação é educação que, em muitos momentos, desafia os valores morais vigentes, questionando-os à luz do verdadeiro senso ético. O sujeito moral reconhece as regras, normas e hábitos que reforçam as estruturas de poder. O sujeito ético, no entanto, pensa criticamente tais estruturas e, se preciso, reinventa-as, transformando a moralidade. Para a obtenção desse propósito, seu modelo de professor da Escola Nova se sustenta em dois alicerces: a) o saber moral e prático permeado por práticas educativas e; b) saber técnico-científico permeado pelo conhecimento e pelo controle dos fenômenos educacionais.

A formação para os processos de ensino e aprendizagem ainda está organizada em torno de lógicas disciplinares; fragmentadas; as disciplinas não têm relação entre si e têm pouco impacto para os alunos. A procura da contextualização teórica e prática para que o ensinado na universidade se aplique bem na vida cotidiana, permitindo que as disciplinas científicas sejam formuladas numa linguagem e em função de problemas que possuam pertinência e utilidade para os professores e estudantes na contextualização ético-científica, desestimulando-os ao ensino eclesiástico, estatal e subordinado, deve se ater ao conjunto de saberes baseado em fatores: a) temporais - ocorre ao longo do tempo estruturado em experiências antes de o sujeito ser professor; b) plurais e heterogêneos - provêm de diversas fontes, necessitando de várias estratégias de ação resultando a atenção a vários objetivos; c) personalizado - cada professor tem uma personalidade formada e uma atuação qualitativa não equivalente; d) situado - a contextualização é marcada fortemente pelo conhecimento da própria realidade onde se trabalha, entretanto, sem desprezar os problemas globais; e) exercício da cidadania - em respeito à vontade própria do humano para o humano, do individual para o coletivo cooperativo e; f) racionalidade dialógica e pensamento sistêmico - sustentado por: liderança, diálogo, pensamento e ação (ALARCÃO, 2001). O educador que vislumbra essa construção é, naturalmente, alguém que acredita no poder da transformação.

Assim, considerando o professor o responsável por um amplo espaço de relações humanas onde decisões e julgamentos são feitos a todo tempo, para se analisar a ética e a moral na escola, é preciso considerar o que se faz na escola, de forma refletida e em busca da defesa de finalidades ou bens maiores inscritos nos valores morais.

A inquietação com a forma como vem sendo tratada a ética, tanto no 
contexto da educação quanto na pesquisa científica, faz com que se perceba nítida redução à moralidade que, via de regra, segundo Marin (2004) resulta na reprodução de padrões e normas estabelecidas, servindo à manutenção do status quo e de relações de domínio-submissão, com a preocupação de que esse quadro não seja incorporado definitivamente pela educação.

A evolução da prática dos professores ocorreu por meio de uma negociação de interesses comuns entre as exigências do Estado, da sociedade civil e do corpo docente (LAWN, 1987). No entanto, o advento da globalização apresentou mudanças significativas na reorganização da formação de professores. Parte do movimento de reforma centrou-se na educação de qualidade para todos os alunos, e mais, a reforma é estruturada em termos de melhores resultados disciplinares para os alunos (HARGREAVES e EVANS, 1997).

Estratégias salientando melhor resultado do estudante exigem que o trabalho dos professores torne-se mais fortemente alinhado com as práticas padronizadas de sala de aula. Há uma demanda dos professores por cursos destinados a adequar o seu desenvolvimento profissional às necessidades dos estudantes e de suas escolas, talvez à custa dos seus planos de carreira e interesses próprios (ASCHER, 1997).

Além da necessidade de reformulação das práticas do trabalho dos professores, da perda econômica, da percepção pública sobre a profissão docente em função da mudança de escala social e a maneira que a profissão tem procurado dar resposta às preocupações da comunidade respondendo às demandas da comunidade sobre os níveis de profissionalismo e confiança dos professores e do ensino, gera críticas públicas que articula preocupações percebidas com a queda no padrão de educação e responsabiliza os professores pelo declínio na educação (ZEICHNER, 2004).

A resposta ao "problema mestre" provoca mudanças na política para a prática docente e reflete um padrão de respostas nacionais, políticas governamentais e revisão de normas de ensino (GREEN, 1999). Essas respostas ilustram a influência da globalização na educação, onde as preocupações sobre o aproveitamento da economia global apresentaram um conjunto de questões que confrontam a ação dos professores, necessitando redesenhar os sistemas de ensino para que esses sistemas melhor se articulem com as demandas de conhecimento científico e ético.

Articulando um componente ético para a identidade dos professores, apresenta-se uma estratégia política para forjar os seus interesses coletivos em um contexto de educação e mudança social, criando uma estratégia política envolvida na construção de um código de ética de professores, que mantém crenças fundamentais acerca da educação e do ensino. Como insinuado anteriormente, a profissão docente tem evoluído fora das negociações entre as demandas dos diferentes intervenientes na educação. Onde, uma vez que a negociação dos professores era com os governos, hoje, adicionou-se outra camada de agentes educativos, que faz recomendações políticas de como as nações devem abordar a reforma da educação à luz da economia globalizada (MARGINSON, 1999). 
A fidelidade na observância aos preceitos éticos gerais e profissionais, visa à criação de solidariedade entre os professores e garante que a profissão mantenha o poder político em representar as vozes desses professores na determinação de como a profissão docente deve se desenvolver no século XXI.

$\mathrm{Na}$ formação do professor participativo, alguns princípios éticos se mostram a desejar: a) como ferramenta para ajudar os professores e o pessoal da educação, quanto às questões de conduta profissional; b) gerar debates de questões éticas em curso entre os educadores; c) nenhum código pode cobrir toda eventualidade e este não é diferente; d) destina-se a ajudar os educadores a abordar as relações com os diferentes intervenientes na educação. Ao fazer estas afirmações, é dada atenção para a necessidade de conversações sobre o que significa ser um professor, seu compromisso com a profissão, seu compromisso com os estudantes, seu compromisso com os colegas, seu compromisso com a gestão de pessoal, seu compromisso com os pais, e, finalmente, garantir o compromisso da comunidade para com seus professores (TARDIF, 2002).

\section{CONSIDERACִ̃̃ES FINAIS}

A Ética como processo de reflexão, de esclarecimento e de debate sobre o relacionamento do homem com a ciência é fundamental no contexto da educação em ciência. Segundo a visão dos autores Bertrand e Valois (1999), significa que a reflexão e o esclarecimento sobre a ética na ciência devem emergir em todas as atividades relativas ao ensino e à aprendizagem de conhecimentos, levando em conta a multidimensionalidade do ser humano, o que significa que os esforços educacionais na ética não se traduzem apenas no desenvolvimento racional e cognitivo, senão também, do seu emocional, social, ético-morais, espirituais, estéticos, entre outros.

A multidimensionalidade do ser humano leva-nos a considerar as complexas relações que podem surgir entre os seres humanos e o universo. A relação com os fenômenos biofísicos não é apenas racional ou do tipo afetivo ou emocional. Pelo contrário, é uma mistura de um complexo padrão de comunicação. O conhecimento humano é complexo, pois envolve vários tipos de relatórios ao mesmo tempo.

Uma educação ética na ciência, como processo em atender a essa multidimensionalidade dos seres humanos e sua complexidade em explicar e entender o universo apresenta como estratégia de ensino o diálogo que leva à reflexão, esclarecimento, expressão e debate de idéias, imagens, representações, mitos, medos, etc. Essa ação dialógica não é limitada, assim, apenas à linguagem falada, mas ampliada às outras formas de comunicação. Daqui resulta que essa estratégia dialógica é complexa e especial para cada situação de ensino.

A ciência e a educação estão adicionando à vontade social e sociedades políticas para controlar seus próprios destinos, seus meios e poder para fazer isso. A ciência e a educação estão proporcionando à sociedade uma grande variedade 
de opções quanto ao que poderia ser o destino da humanidade. Derramam efeitos ramificadores sobre as práticas sociais da humanidade, bem como sobre novas qualidades de conhecimento do homem. Não obstante, deve ser perseguida a educação dos "produtores" da ciência para os aspectos simbólicos e conceituais, que são agrupados aos problemas enfrentados pelo público sobre a inovação.

A ciência e a educação necessitam superar tentativas de serem estudadas fora do contexto social em que ocorrem. O efeito de ambas, atuando juntas, é infinitamente superior à soma dos efeitos de cada uma agindo separadamente. A Educação em ciência também tem o papel de desenvolver nos indivíduos a autocrítica dos paradigmas dominantes. Como missão, poderia levar indivíduos à consciência de participação, voluntária ou não, em um processo acelerado de sistemas de equilíbrio do meio em que vivem. Um dos caminhos para tornar essa educação possível é através de uma dimensão transversal da ética. Esta transversalidade é justificada por duas razões fundamentais: porque é contínua no processo educacional e porque leva em conta a multidimensionalidade do ser humano e a complexidade da construção do conhecimento.

No que se refere à formação de professores no contexto de interrelação com a ética, com a educação e com a ciência, perante todas as transformações e todos os problemas gerados por consequência da modernidade, de onde também derivam as concepções da ciência e da ética que se adotam, é necessário que se identifiquem com clareza os possíveis equívocos adotados, para que se possa implementar modelos na formação inicial para se evitar o aumento da "deformação" de educadores diante do caráter social do desenvolvimento científico.

$\mathrm{Na}$ perspectiva da reflexão acerca de alternativas para a formação docente, aponta-se para a importância da busca pela cultura do pensar e não apenas do saber, em uma lógica que leve, de fato, os futuros educadores a considerar que as questões éticas são indissociáveis do ensino da e sobre a ciência, considerando este como caminho da formação de "sujeitos autônomos, capazes de pensar por conta própria e de acionar estratégias políticas que os levem a atuar criativamente na invenção de novos espaços democráticos” (RODRIGO, 2003, p. 102).

A estruturação de uma cultura do pensar se coloca como uma das esferas de construção para a sociedade contemporânea e, consequentemente, para a escola. Diz-nos Morais sobre alternativas para a formação dessa cultura: "Ora, tendo a filosofia sido o caldo prímero do qual sugiram as ciências [...], a filosofia, é e será sempre a consciência das ciências. A filosofia é, então, elemento básico de construção de sentido, de articulação cultural do saber.” (MORAIS, 2003, p. 31). Este autor aborda também a filosofia enquanto elemento da formação docente dizendo: "Ora, com tais características, a sua falta na formação dos professores (ainda que não sejam docentes de filosofia) dificilmente permitirá a emergência de profissionais de rica e lúdica visão"(MORAIS, 2003, p. 31).

A escolha pela formação da cultura do pensar requer, ainda, que se introduzam nos currículos da escola contemporânea e, também, concretamente, nas salas de aula, conhecimentos que instiguem a reflexão sobre os elos da ciência com 
a ética. Nessa perspectiva, as possíveis contribuições da filosofia nos diferentes níveis da educação, direcionadas para seu espaço na formação de professores, estão ligadas à ampliação das discussões por uma educação que possibilite a cada um, em sua individualidade e na sua relação com o meio e com o outro, pensar por si próprio, tendo neste outro o grande referencial de ação. Ou, como diz Kant: “[...] age de tal modo que possas usar a humanidade, tanto em tua pessoa como na pessoa de qualquer outro, sempre como um fim ao mesmo tempo e nunca somente como um meio" (KANT, sd, p. 71).

Nessa perspectiva, não parece ser o bastante o formador deter conhecimentos para serem reproduzidos, é necessário compreender o conhecimento, ser capaz de desconstruir, reorganizar as partes e reconstruir de forma coerente com a sua realidade didática e com um modelo de mundo que se deseja construir, considerando o confronto conceitual (paradigma) e considerando as novas idéias para o combate de certos dogmatismos que a modernidade (também) institui. Conclusivamente, se faz necessário o desenvolvimento da consciência progressiva e reflexiva da prática de cada indivíduo em um contexto no qual o esforço individual deve ser orientado pela práxis coletiva.

\section{REFERÊNCIAS BIBLIOGRÁFICAS}

ALARCÃO, I. Escola Reflexiva e Nova Racionalidade. Porto Alegre: Artmed, 2001.

ARENDT, H. La crise de l'éducation. Paris: Gallimard, 1990.

ASCHER, F. Le mouvement dans les sociétés hypermodernes. Université de tous les savoirs, 1997. Canal U . Disponível em: <http://www.canalu.tv/themes/sciences_humaines_sociales_de_l_education_et_ de_l_information/sciences_de_la_societe/sociologie_demographie_anthropologie/sociologie/e_ la_science_dans_la_societe_moderne.> Acesso em 10/12/2009.

BARRET, P. Mondialisation et inégalités en France. Discurso proferido no Programmes des colloques de la Fondation Res Publica. Paris, 21 de setembro de 2009. Disponível em: <http://www.fondation-res-publica.org/Colloques-de-la-Fondation-Res-Publica_r3.html.> Acesso em 29/12/2009.

BECHTEL, M. F. De la société du savoir à la question de l'Ecole. Discurso proferido no Séminaires de la Fondation Res Publica, Paris, 4 abril 2006. Disponível em:<http://www.fondation-res-publica.org/ Mondialisation-et-inegalites-enFrance_r61. html.> Acesso em 28/12/2009.

BERTRAND, Y.; VALOIS, P. Paradigmas Educacionais. Lisboa: Horizontes Pedagógicos, 1999.

BKOUCHE, R.; CHARLOT, B.; ROUCHE, N. Faire des mathématiques, le plaisir du sens. Paris: Armand Colin, 1991.

BRIS, M. L. E seus filhos não sabem ler ou contar? In. FRANCE, N. L. Nenbuma sociedade do conbecimento sem escolas. Nice: France Loisirs, 2006.

CHAUÍ, M. Convite a Filosofia. 12 ed., São Paulo: Ática, 2001.

CHEVÈNEMENT, J. P. Pas de société du savoir sans école. Intervention prononcée lors du colloque. Paris, 2006. FORSTER, M. M. S. Universidade/ escola: diálogos e reflexões compartilhados - a formação docente. VI Fórum Nacional de Educação. São Leopoldo, 2009.

FOUREZ, G. La construction des sciences : les logiques des inventions scientifiques. $4^{\mathrm{a}}$ ed., Bruxelles: Éditions De Boeck Université, 2002.

GREEN, F. The Educational Formation of Conscience The Educational Formation of Conscience. Norwich, 1999. Disponível em: <https://www.commerce .metapress.com/content/k452t58066631n22/resource-ecured $/$ ?target $=$ fulltext.pdf\&sid $=\mathrm{d} 523 \mathrm{n} 0$ bclotlrq $45 \mathrm{k} 2 \mathrm{efsh} 55 \& \mathrm{sh}={ }_{\mathrm{www}} \mathrm{springerlink} . \mathrm{com} .>$ Acesso em 16/12/2009. 
HABERMAS, J. De l'éthique de la discussion. Paris: Flammarion, 1999.

HARGREAVES, A. e EVANS, R. Internation handbook of educational change. V1. Kluwer Academic Publishes Bodmin, 1997. Disponível em: < http://www.books.google.com.br/books?id=7Wk9fDcBl9EC\&pg=PA293\&lpg=PA293\&dq=HARGREAVES+e+EVANS,+1997+education\&source=bl\&ots= 4XK7wXlg8N\&sig=6gmoqHHJfKC0cD5CHEZkzsnYHLo\&hl=pt-R\&ei=BleuS5y7IoWIuAeiwK

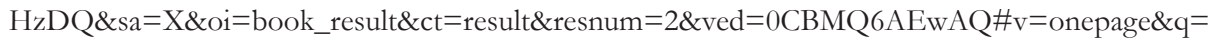
HARGREAVES\%20e\%20EVANS\%2C\%201997\%20education\&f=false.> Acesso em 12/12/2009. KAHN, P. De l'enseignement des sciences à l'école primaire. Paris: Éditions Hatier, 1999.

KANT. I. Fundamentos da metafísica dos costumes. Trad. Lourival de Queiroz Henkel. Rio de Janeiro: Ediouro, s.d. LAKATOS, E. M.; MARCONI, M. de A. Metodologia cientifica. 5a Ed. São Paulo: Atlas, 2010.

LARROSA. J. Pedagogia Profana. Belo Horizonte: Autêntica, 2000.

LATOUR B. It's development, stupid! or: How to Modernize Modernization. Nordhaus, and Shellenberger. New York: Houghton Mifflin Company, 2007.

LAWN, M. Teachers: The culture and politics of work. London: The Falmer Press, 1987. Disponível em: <http://www.springerlink.com/index/P4L465T862682QQ5. pdf.> Acesso em 20/12/2009.

MACEDO, B.; KATZKOWICZ, R. Educação científica: sim, mas qual e como?. In: MACEDO, B. (Org.) Cultura científica: um direito de todos. Brasília: UNESCO, OREALC, MEC, MCT, 2003.

MARGINSON, S. Diversity and convergence in Australian higher education. Australian Universities Review, 42 (1), 1999. Disponível em: <http://www.eric.ed.gov/ERICWebPortal/custom/portlets/ recordDetails/detailmini.jsp?_nfpb=true\&_\&ERICExtSearch_SearchValue_0=EJ591489\&ERICE xtSearch_SearchType_0=no\&accno=EJ591489.> Acesso em 22/12/2009.

MARIN, A. A. Ética, moralidade e educação ambiental. INCI, Caracas, vol. 29, nº.3, mar. 2004. p.153-157. MAYZ-VALLENILLA, E. Esbožo de una crítica a la razón técnica. Caracas: Equinoccio, 1974.

MORAIS, R. de. Filosofia e formação humana: a criança. In: EVANGELISTA, F. e GOMES, P. de T. (Orgs.). Educação para o pensar. Campinas: Alínea, 2003. p. 25-34.

NÓVOA, A. Profissão Profesor. $2^{a}$ ed. Porto: Porto Editora, 1999.

PENA-RUIZ, H. L'Ecole. Paris: Flammarion, 1999.

RODRIGO, L. M. Educação e cidadania. In: EVANGELISTA, F. e GOMES, P. de T. (Orgs.). Educaşão para o pensar. Campinas: Alínea, 2003. p. 95-102.

ROTH et DÉSAUTELS (édit.) Science Education as/for Sociopolical Action. New York: Peter Lang Publishing, 2002. RUSS, J. Pensamento ético contemporâneo. $2^{a}$ ed. São Paulo: Paulus, 1999.

TARDIF. M. Saberes docentes e formação de professores. $8^{a}$ ed. São Paulo: Vozes, 2002.

TIM, P. U'educazione italian. Milan: Bompiani, 2003.

ZEICHNER, K.M. Uma agenda de pesquisa para a formação docente. Revista Brasileira de Pesquisa Sobre Formação de Docentes. Volume 01, $\mathrm{n}^{\circ}$. 01 Artigos 2004. Disponível em:<http://www.formacaodocente.autenticaeditora.com.br/ editorial. > Acesso em 03/01/2010.

ZUCCO, F. Replacing, reducing and refining use of animals in research. Roma: Genomics \& Biotechnology for Health. 2008. Disponível em: < http://www.europa. eu.int/comm/research/rtdinfo/index_ en.html.> Acesso em 14/12/2009.

Data de Recebimento: 14/04/2010

Data de Aprovação: 04/07/2011

Data da Versão Final: 20/08/2011 